\title{
Coagulation Processes for Treatment of Waste Water from Meat Industry
}

Zueva SB ${ }^{1,2 *}$, Ostrikov $\mathrm{AN}^{2}$, Ilyina $\mathrm{NM}^{2}$, De Michelis $\mathrm{I}^{1}$ and Vegliò $\mathrm{F}^{1}$

${ }^{1}$ Laboratory of Integrated Treatment of Industrial Wastes and Wastewaters, Department of Industrial and Information Engineering and Economics of the University of L'Aquila, Italy

${ }^{2}$ Department of Environment and Chemical Engineering, Voronezh State University of Engineering Technology, Russia

\begin{abstract}
Application of the coagulants in treatment of wastewater from food industry is one of the most promising techniques to establish environment-friendly industries. This article describes results of experiment and the chemistry of wastewater treatment with coagulants and so called "coagulant aids". The coagulation efficiency was determined combining different techniques (photocolorimetric method, the microscopying of the samples, zeta potential measurements). The results showed that aluminum sulfate was nearly twice more effective in presents of alumina powder. The reason for this behavior can be explained by the negative value of Zeta potential on its surface. It was found that the aggregation and sedimentation speed can be greatly enhanced.
\end{abstract}

Keywords: Alumina; Coagulation; Sorption; Zeta potential

\section{Introduction}

Coagulation has been subject of many research, most of which has been related to wastewater treatment [1-5], however, it may differ from depending on chemical and physical parameters of contaminants. The particles to be removed include organic material, which can react differently to a coagulant.

Wastewater of a meat plant is full of contaminants, such as fats, carbohydrates, proteins, organic acids. Macromolecules of protein roll up into compact globules, which are negatively charged and have hydrated coating. Their aggregative stability is provided by a series of factors: a decrease in surface energy of dispersed phase (i.e. reduction of driving force in coagulation) as a result of formation of an electric double-layer by the presence of kinetic barriers for coagulation in the form of electrostatic repulsion between colloidal particles and counterions of the similar charges. One more reason for stability of colloids is connected with the process of hydration (solvation) of ions. The coat of the diffusion layer composed of solvated counter-ions also prevents adhesion of the particles. However, if the charge on colloidal particles is destroyed, they are free to come nearer and grow in size. The following forces play an important role in the interaction of colloid particles: included volume repulsion, electrostatic interaction, Van der Waals force, entropic force, steric interactions.

In wastewater treatment coagulation process is particles adhesion process with formation of large flocs, as a result of addition of a chemical reagent (coagulating agent) for the purpose of destabilization of suspended colloidal particles and their subsequent coagulation (aggregation).

Inorganic coagulating agents (low-molecular inorganic and organic electrolyte), are neutralize negatively charged colloidal particles in water with following particles aggregation (coagulation) and precipitation. For example, aluminium sulfate $\left(\mathrm{Al}_{2}\left(\mathrm{SO}_{4}\right)_{3} \cdot 18 \mathrm{H}_{2} \mathrm{O}\right)$, consists in hydrolysis of sulfates with formation at low $\mathrm{pH}$ positively charged sol of aluminum hydroxide $\left[\mathrm{mAl}(\mathrm{OH})_{3} 2 \mathrm{nAl}(\mathrm{OH})_{2}^{+}(2 \mathrm{n}-\mathrm{x}) \mathrm{SO}_{4}^{2-}\right]^{2 \mathrm{x}+}$.

Together with coagulants can be used various clay, pastes, a metal dust, ashes, small quartz sand [4]. They can play a role of the additional centers of condensation of products of hydrolysis, promotes acceleration of coagulation, speed of their sedimentation. Some of them can be an adsorbents and increase effectiveness of purification of waste water from dissolved impurities.
During the precipitation of metal hydroxides organic macromolecules are enclosed in the flocks [6] and removed in the subsequent filtration process.

High-molecular organic or inorganic compound give simultaneous adsorption on two or several particles of disperse phase connects them in aggregates by polymeric bridges and as a result reduces stability of disperse system. Such bridges can form both macromolecules of water-soluble polymers, and insoluble substances in water, for example Aluminum Oxide powder $\left(\gamma-\mathrm{Al}_{2} \mathrm{O}_{3}\right)[7]$.

One of the major uses of activated metal oxides is for adsorbing metal or nonmetal ions from aqueous wastewater streams. For instance, activated alumina is suggested by the Environmental Protection Agency (EPA) as a Best Available Treatment (BAT) for removing selenium and arsenic ions from water [8].

The free energy of adsorption for charged ions onto highly charged metal oxides is due to three main contributions: specific chemical interaction, columbic attraction or repulactivated and desolvation of the ion [9].

As it was shown in the metal ions are chemically bound to the $=A l-O^{-}$group by an ionic exchange with $H^{+}$group which is favored by the basic conditions of the medium. The metal ions retain a positive charge, then coagulation can occur by electrostatic interaction between the positive sites $=A l-O-M^{+}$on one particle and the negative groups $=\mathrm{Al}-\mathrm{O}^{-}$on another; in this process, the metal ions are acting as bridging units between the particles. This is the mechanism to flocculate and to adsorb the metal ions in solution on the particles surface [10-13].

*Corresponding author: Svetlana Zueva, Laboratory of Integrated Treatment of Industrial Wastes and Wastewaters, Department of Industrial and Information Engineering and Economics of the University of L'Aquila, Italy, Tel: +39346 2104194; E-mail: svetlana.zueva@graduate.univaq.it

Received October 09, 2013; Accepted December 04, 2013; Published December 09, 2013

Citation: Zueva SB, Ostrikov AN, Ilyina NM, De Michelis I, Vegliò F (2013) Coagulation Processes for Treatment of Waste Water from Meat Industry. Int J Waste Resources 3: 130 doi: 10.4172/2252-5211.1000130

Copyright: $\odot 2013$ Zueva SB, et al. This is an open-access article distributed under the terms of the Creative Commons Attribution License, which permits unrestricted use, distribution, and reproduction in any medium, provided the original author and source are credited. 
Knowledge of the zeta potential provides an important parameter for the explanation of the adsorption mechanism of an adsorbate at the metal oxide-water interface [14]. The isoelectric point (i.e.p.) or point of zero charge $(\mathrm{pzc})$ of the any metal oxide surfaces provides information on the cleanness of a metal oxide surface.

In this study the zeta-potential method was used to determine coagulations and sorption processes in meat industry wastewater treatment. This rate information was then analyzed to establish the mechanisms of coagulation and adsorption.

\section{Materials and Methods}

Activated $\gamma$-alumina $\left(\gamma-\mathrm{Al}_{2} \mathrm{O}_{3}\right)$ and aluminum sulfate $\left(\mathrm{Al}_{2}\left(\mathrm{SO}_{4}\right)_{3} 20\right.$ $\% \mathrm{w} / \mathrm{v}$ ) were used as the reagents for all phases of studies.

The subject of the research is wastewater of a dairy plant with the following pollution characteristics: Suspended Substance (SS) $=1350$ $\mathrm{mg} / \mathrm{L}$, Fats $=64.3 \mathrm{mg} / \mathrm{L}$, Iron salts $=2.59 \mathrm{mg} / \mathrm{L}, \mathrm{pH}=6.5-7.0, \mathrm{t}=20^{\circ} \mathrm{C}$.

The mass fraction of fat in the experimental samples was estimated using the Gerber method. The method is based on the allocation of fat under the action of strong sulphuric acid and isoamyl alcohol in the form of a continuous layer, the amount of which is measured in the graded part of the butyrometer.

The content of suspended substances in the samples was estimated using the turbidimetric method. The optical density (D) was measured at a fixed wavelength of $500 \mathrm{~nm}$ using a UV-visible spectrophotometer.

The content of Iron salts was monitored by photometric method at the wavelength $420 \mathrm{~nm}$. This method based on the fact that sulfosalicylic acid in weakly alkaline medium form a colored complex salts with iron (III) and (II) (yellow color).

The zeta potentials and the average size of the particles were measured with Zetasizer (Malvern Instruments) based dynamic light scattering and electrophoretic light scattering method using M3-PALS technology.

The microscopying of the samples has been conducted with Biomed 4 trinocular microscope with a lens increased by x10 and additional increase of the camera $\mathrm{x} 4$. Biomed 4 is designed to monitor substance in transmitted light in the bright and dark field, phase contrast.

\section{Results and Discussions}

Wastewater from meat industry can be considered as a dispersed system (suspension). It is known that above $\mathrm{pH} 7$ nano-particles in a sol-gel system are charged negatively. This negative charge stabilizes the dispersion by electrostatic repulsion, preventing the aggregation of the particles.

According results of measuring the initial particle size was of 3.54 $\mu \mathrm{m}$ with the zeta-potential of $-15.9 \mathrm{mV}$ at $\mathrm{pH}=6.8$ (Figures 1 and 2). Indeed, particles with zeta potentials less than $-30 \mathrm{mV}$ are normally considered stable, the process of coagulation occurs rather slowly. Multi component structure of wastewater acts as a stabilizing factor here. To stimulate the process (of rapid coagulation) it was necessary to add special reagents - coagulants or flocculants - which should band together small particles of dispersed system into bigger ones under the influence of cohesive forces.

For the purpose of studying the process of coagulation purification of waste water of the meat plant series of experiments to identify the

\begin{tabular}{|c|c|c|c|c|c|}
\hline Z-Avarage & & & Diam.(nm) & $\%$ Volume & Width (nm) \\
\hline (d.nm) & 6754 & Peak 1: & 3 & 100,0 & 588,2 \\
\hline Pdl: & 0,297 & Peak 2: & 0,000 & 0,0 & 0,0 \\
\hline Intercept & 0,983 & Peak 2: & 0,000 & 0,0 & 0,0 \\
\hline
\end{tabular}

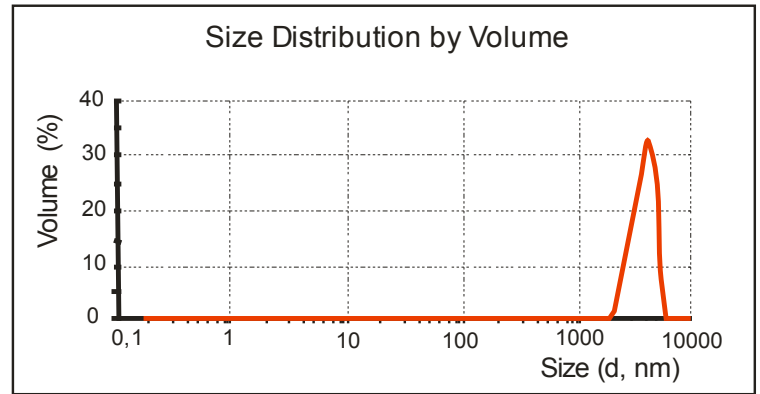

Figure 1: The results of measuring the size of particles in dispersed phase of the dairy plant waste water.
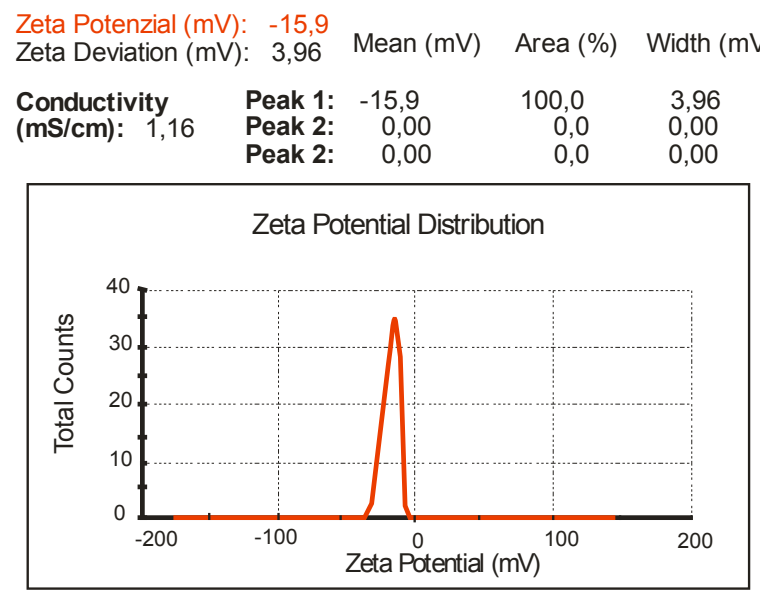

Figure 2: The results of measuring the value of Zeta potential of dispersed phase of the dairy plant waste water.

particles size and value of zeta-potential of resulting agglomerations against the dose and the type of the reagent were conducted.

Aluminum sulfate at low $\mathrm{pH}(<7,8)$ form positively charged sol of aluminum hydroxide, which can neutralize negatively charged particles in wastewater with following aggregation (coagulation). Flock growth rate as a function of time for different dosage of aluminum sulfate presented on the Figure 3.

When the sizes of the flocs were large enough, the sedimentation effects become possible. The maximum of the flocs size were in correlation with their maximum sedimentation speed and with isoelectric point (i.e.p.) (Figure 4).

Effectiveness of wastewater treatment as a function time is shown on the Figure 5. Simultaneously with coagulation and precipitation adsorption effects took place. However, according with result of experiments the fats removal was much more effective than adsorption of iron salts at any dosage of aluminum sulfate. This phenomenon seemed to indicate that aluminum sulfate effective to enhance solids and fats removal and not so effective in removing of soluble components.

The properties of any specific fat molecule depend on the particular fatty acids that constitute it. Long chains of fatty acids are susceptible to intermolecular forces of attraction (in our case, van der Waals forces). 


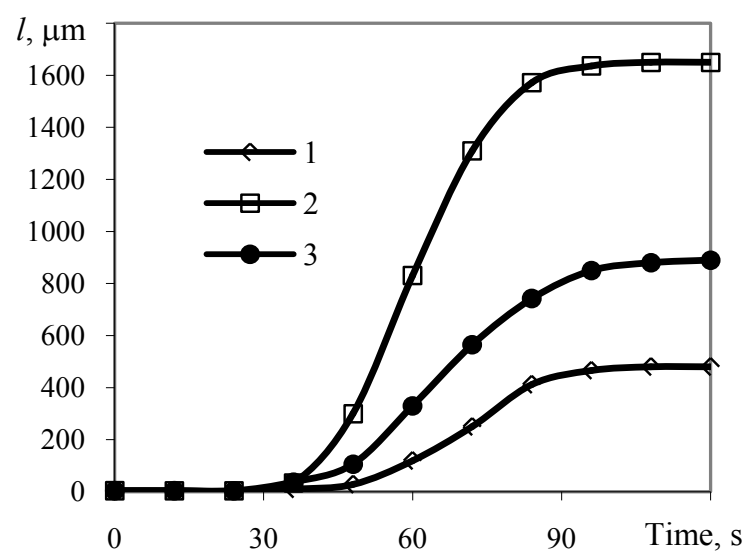

Figure 3: Flocs size as a function of time for different doses of aluminum sulfate: $1-10 \mu \mathrm{L} / \mathrm{L} ; 2-30 \mu \mathrm{L} / \mathrm{L} ; 3-50 \mu \mathrm{L} / \mathrm{L}$.

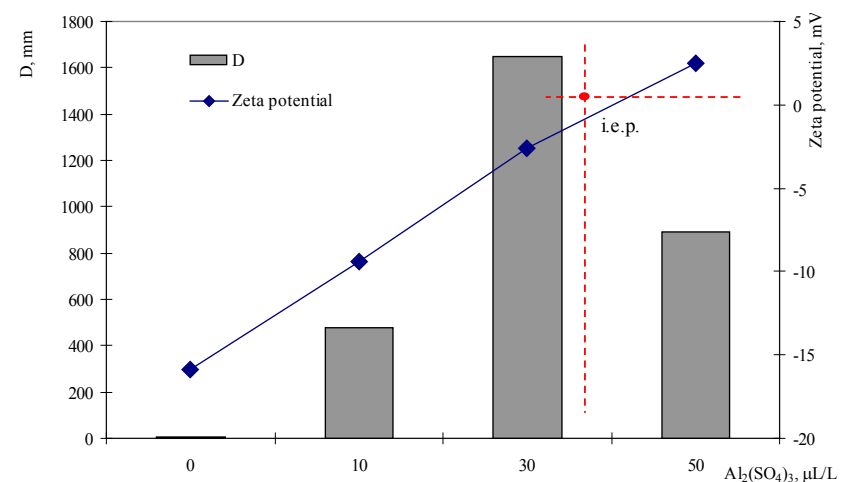

Figure 4: The influence of the dose of aluminum sulfate $(10,30$ and $50 \mu \mathrm{L} / \mathrm{L})$ on Zeta potential of the formed flakes (after $4 \mathrm{~min}$ ).

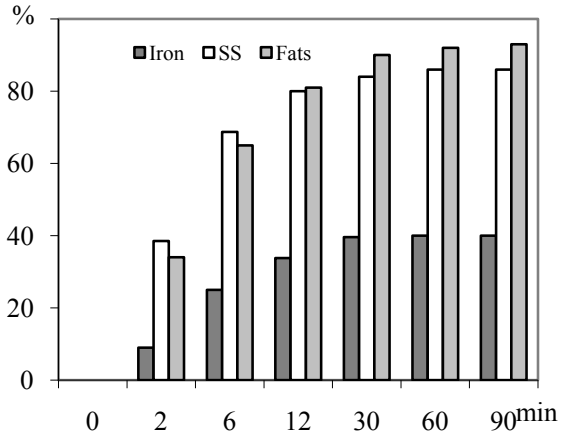

Figure 5: Effectiveness of wastewater treatment as a function time at the dosage of aluminum sulfate $30 \mu \mathrm{L} / \mathrm{L}$.

Obviously the mechanism of coagulation both SS and fats include double layer compression and charge neutralization.

In order to increase effectiveness of purification activated $\gamma$-alumina $\left(\gamma-\mathrm{Al}_{2} \mathrm{O}_{3}\right)$ obtained from the waste of aluminum alloys etching process [15] was studied as a "coagulant aid". The mean particle diameter of this sample was determined to be $0.6 \mu \mathrm{m}$ and the specific surface area measured by BET method was $2.95 \mathrm{~m}^{2} / \mathrm{g}$.

According to Charge Distribution Multisite Complexation model
[8], on a surface of particles of $\gamma-\mathrm{Al}_{2} \mathrm{O}_{3}$ (hydro gels in water solutions), there are few versions of adsorption sites: on plane sides of $\gamma-\mathrm{Al}_{2} \mathrm{O}_{3}$ there is one version active adsorption sites at $\mathrm{pH}>9$; on costal are two versions, active in all interval $\mathrm{pH}$.

Depending on $\mathrm{pH}$ suspensions it is formed positively or negatively charged surface, which charge is compensated by oppositely charged ions from a solution. At $\mathrm{pH} 3.5$ the zeta potential of alumina particles is appropriately positive.

The results of the research have shown that the average diameter of the particles of powder of the sorbent was $5.22 \mu \mathrm{m}$, and the initial value of Zeta potential on the surface of the sorbent in wastewater was -15.6 $\mathrm{mV}$ at $\mathrm{pH}=6.7$.

The kinetic and isotherm of the adsorption process of $\mathrm{Fe}^{3+}$ ions on the $\gamma-\mathrm{Al}_{2} \mathrm{O}_{3}$ are presented on the Figures 6 and 7 .

The results of experiment showed expediency joint usage of sorbents and coagulants (Table 1).

The value of zeta potential decreased due to positive charge ions sorption. The metal ions are chemically bound to the $=\mathrm{Al}-\mathrm{O}^{-}$group by an ionic exchange with $\mathrm{H}^{+}$group which is favored by the basic conditions of the medium [16]. We can suppose, that $\mathrm{Fe}^{2+}$ ions retain a positive charge, then coagulation can occur by electrostatic interaction between the positive sites $=\mathrm{Al}-\mathrm{O}-\mathrm{Fe}^{+}$on one particle and the

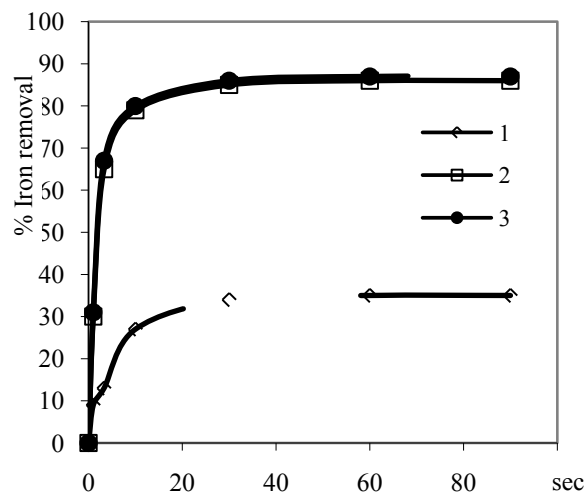

Figure 6: Kinetic plot of $\mathrm{Fe}^{3+}$ ions adsorption on $\mathrm{y}-\mathrm{Al}_{2} \mathrm{O}^{3}$ at three different dosages $1-10 \mu \mathrm{L} / \mathrm{L} ; 2-30 \mu \mathrm{L} / \mathrm{L} ; 3-50 \mu \mathrm{L} / \mathrm{L}$.

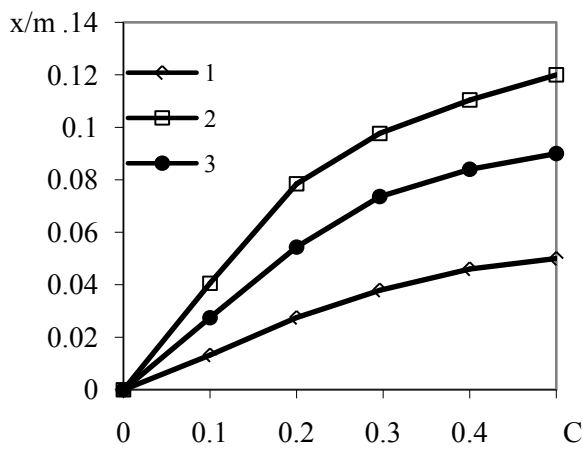

Figure 7: Isotherm plot of $\mathrm{Fe}^{3+}$ ions adsorption on $\gamma-\mathrm{Al}_{2} \mathrm{O}_{3}$ at three different dosages, were $\mathrm{x}=$ mass of adsorbate; $\mathrm{m}=$ mass of adsorbent; $\mathrm{c}=$ Equilibrium concentration of adsorbate in solution. 
Citation: Zueva SB, Ostrikov AN, llyina NM, De Michelis I, Vegliò F (2013) Coagulation Processes for Treatment of Waste Water from Meat Industry. Int J Waste Resources 3: 130. doi: 10.4172/2252-5211.1000130

Page 4 of 4

\begin{tabular}{|c|c|c|c|c|c|}
\hline Way of treatment of waste water & Zeta potential, mV & Size of particles, $\mu \mathrm{m}$ & Iron removing, \% & SS removing, $\%$ & Sedimentation speed, $\mathrm{cm} / \mathrm{min}$ \\
\hline Wastewater & -15.9 & 3.54 & - & - & - \\
\hline $\mathrm{Al}_{2} \mathrm{O}_{3}$ & -42.8 & 0.61 & - & - & - \\
\hline Wastewater $+\mathrm{Al}_{2} \mathrm{O}_{3}$ & -15.6 & 0.61 & 26 & 12 & - \\
\hline Wastewater $+\mathrm{Al}_{2}\left(\mathrm{SO}_{4}\right)_{3}$ & -2.6 & 1650 & 40 & 86 & 15 \\
\hline Wastewater $+\mathrm{Al}_{2}\left(\mathrm{SO}_{4}\right)_{3}+\mathrm{Al}_{2} \mathrm{O}_{3}$ & $-1,07$ & 1890 & 85 & 95 & 75 \\
\hline
\end{tabular}

Table 1: The composition of the wastewater before and after treatment.

negative groups $=A l-O^{-}$on another; in this process, the Fe ions are acting as bridging units between the particles.

This is the mechanism to flocculate and to adsorb the metal ions in solution on the adsorbent's particles surface. As a result we had a very high effect of iron salts removing.

Indeed the value of zeta potential was still too high for flocculation of particles (in waste water there are particles of sorbent with zeta potential $-15.6 \mathrm{mV}$ and suspended particles $-15.9 \mathrm{mV}$ ) and beginning of sedimentation process.

The residual concentration of iron salts in wastewater (effect of removing $90 \%$ ) can be explained by following. At low concentrations only the most thermodynamically favorable active surface groups participate in the adsorption process. The ion potential value for $\mathrm{Fe}^{2+}$ is 44.8 and for $\mathrm{Fe}^{3+}$ is 21.4 ; the energy of hydration for $\mathrm{Fe}^{2+}$ is -87.9 $\mathrm{kJ} / \mathrm{mol}$, and for $\mathrm{Fe}^{3+}$ is $-135.6 \mathrm{~kJ} / \mathrm{mol}$ [17]. So $\mathrm{Fe}^{2+}$ has more value of ion potential and less hydration degree and can be more adsorbed by negative charged surface of aluminum oxide. In the end of sorption we have residual concentration of $\mathrm{Fe}^{3+}$.

\section{Conclusions}

Double layer compression and electric charge neutralization appeared to be the major factor in the coagulation process, as suggested by plotting zeta potential measurements and particle size during the experiments.

Joint usage of an inorganic sorbent and aluminum sulfate allows us to increase the value of Zeta potential and the effectiveness of purification almost twice. The sorbent particles act as additional condensation centers for hydrolysis products, which contributes to the increase of coagulation, the flakes of suspended solid particles become heavier, their hydraulic size increases. Besides, dissolved impurities are adsorbed from the wastewater. Use of dual aluminum sulfate - alumina systems can markedly enhance coagulation at a much lower dosage.

\section{Acknowledgement}

Authors are very grateful to Dr. Gudkova E.A., the Center of High Technologies of the Belgorod State National Research University for helpful collaboration during the zeta potential analyses.

\section{References}

1. Dikarevsky VS (2006) Disposal and purification of waste waters: study manua for university students majoring in "Water supply, waste-water disposal systems, efficient use and conservation of natural resources" Stroyizdat, Moscow.

2. Wang YF, Gao BY, Yue QY, Wang Y, Yang ZL (2012) Removal of acid and direct dye by epichlorohydrin-dimethylamine: Flocculation performance and floc aggregation properties. J Bioresour Technol 113: 265-271.

3. Wang YF, Gao BY, Yue QY, Wang Y (2011) Effect of viscosity, basicity and organic content of composite flocculant on the decolorization performance and mechanism for reactive dyeing wastewater. J Environ Sci 23: 1626-1633.
4. Nazarov VN (2007) A laboratory manual and a problem book on colloidal chemistry. Surface phenomena and dispersed systems. ICC, Moscow.

5. Lurie M, Rebhun M (1997) Effect of properties of polyelectrolytes on their interaction with particulates and soluble organics. Water Sci Technol 36: 93-101.

6. Haberkamp J, Ruhl AS, Ernst M, Jekel M (2007) Impact of coagulation and adsorption on DOC fractions of secondary effluent and resulting fouling behaviour in ultrafiltration. Water Research 41: 3794-3802.

7. Hiemstra T, van Rjemsdijk WH (1996) A surface structural approach to ion adsorption: the charge distribution (CD) model. J Colloid Interface Sci 179: 488-508.

8. Goldberg S, Davis JA, Hem JD (1995) The Surface Chemistry of Aluminum Oxides and Hydroxides. University of California, Berkeley, California.

9. Hiemstra T, Venema P, Van Rjemsdijk WH (1996) Intrinsic proton affinity of reactive surface groups of metal(hydr)oxides: the bond valence principle. $J$ Colloid Interface Sci 184: 680-692.

10. Venema P, Hiemstra T, Weidler PG, van Riemsdijk WH (1998) Intrinsic proton affinity of reactive surface groups of metal (hydr)oxides: application to iron (hydr)oxides. J Colloid Interface Sci 198: 282-295

11. Hiemstra T, van Rjemsdijk WH (1999) Surface structural ion adsorption modeling of competitive binding of oxyanions by metal (hydr)oxides. J Colloid and Interface Sci 210: 182-193.

12. Rietra RP, Hiemstra T, van Rjemsdijk WH (1999) The relationship between molecular structure and ion adsorption on variable charge minerals. Geochim et Cosmochim Acta. 63: 3009-3015

13. Shevchenko TV, Mandziy UV, Tarasova MR (2003) Purification of waste waters with non-conventional sorbents. Ecology and Industry of Russia 1: 35-37.

14. Kosmulski M (2002) The pH-dependant surface charging and points of zero charge. J Colloid Interface Sci 253: 77-87.

15. Zueva SB (2011) Production aluminum oxide Russian Federation patent.

16. Pacheco S, Rodrigues R (2001) Adsorption properties of metal ions using alumina nano-particles in aqueous and alcoholic solutions. Sol-Gel Science and Technology 20: 263-273.

17. Kalukova EN, Pismenko VT, Ivanskaya NN (2010) Adsorption of Fe and Mn cations by inorganic sorbents. Sorption and Chromatographic process 10: 194 200. 